\title{
A novel technique for performing symmetric Taylor impact
}

\author{
S.M. Walley ${ }^{\mathrm{a}}$, N.E. Taylor, D.M. Williamson, and A.P. Jardine \\ SMF Fracture and Shock Physics Group, Cavendish Laboratory, University of Cambridge, CB3 OHE, UK
}

\begin{abstract}
A novel spring tensioned wire cradle arrangement has been developed to hold the target rod lightly but firmly in place when performing rod-on-rod (symmetric Taylor) impact in a vacuum. In addition, a soft capture system has been designed and used to decelerate both rods while reducing the chance of them colliding a second time. High-speed photography was used to obtain the profile of a pure aluminium target rod as a function of time. Photon Doppler Velocimetry (PDV) was also deployed to record the velocity of the rear of the target rod as a function of time. Voiding in the interior of recovered rods was investigated non-destructively using X-ray tomography. The data provides comprehensive validation information for predictive constitutive models.
\end{abstract}

\section{Introduction}

The ideal symmetric Taylor impact experiment would be performed by firing two identical rods simultaneously at each other at the same velocity. Since there is a risk of wrecking both gun barrels, rod-on-rod impact is normally employed where one rod is fired against a stationary target rod $[1,2]$. In an ideal rod-on-rod impact, there would be no external constraint on the lateral deformation of the rods i.e. the impacting rod would be in free flight and the target rod would be levitated. It is also required for a valid experiment that the impact be planar and coaxial.

These requirements mean that (a) the impacting rod has to be as close to the end of the gun-barrel at impact as possible or even partially within the barrel (but protruding sufficiently that the section within the barrel does not plastically deform during impact) and (b) the target rod has to be mechanically supported so that the rods can be accurately aligned before the shot is performed. The mechanical support should put as little constraint upon the deformation as possible. In this paper, we describe an experimental setup which meets these criteria.

\section{Experimental design}

Previous researchers have used sabots to deliver the projectile rod to the target [3-8]. However, a sabot that only contains the rear section of a rod [9] will need to hold the rod firmly. This will change the boundary conditions for elastic waves reverberating up and down its length. So we decided to make the projectile rods good sliding fits within the gun barrel used. One aim was that the deformation and contact time should be determined as far as possible only by the mechanics of the impact between the two rods. Impacts were performed in a rough vacuum of about 40 mbar to minimise the effects of airblast ahead of the impacting rod due to residual gas in the barrel or from propellant gas leaking past the projectile rod.

\footnotetext{
${ }^{a}$ Corresponding author: smw14@cam.ac.uk
}

The main requirements for the design of the target rod holder were the following: (i) the mounting system should be sufficiently rigid to hold the weight of the rod and stabilise it against airblast from the gun; (ii) it should put as little mechanical constraint as possible on the dynamic expansion of the target rod; (iii) the mount should allow high-speed photography to be performed so that the development of the deformation can be followed; (iv) the mount should allow soft recovery of both rods so that their final lengths and profiles can be measured.

After some experimentation, a spring-tensioned wire cradle arrangement was found to work well (Fig. 1). The wires used had a PTFE coating giving them a low frictional interaction with the target rod. The cradle was mounted on top of a stack of three Thorlabs optical adjustment stages, namely $\mathrm{x}-, \mathrm{z}-$, and pitch-yaw. These allow sufficient adjustment of the position and orientation of the target rod so that it can be made both collinear and coaxial with a $25 \mathrm{~cm}$ long alignment rod of the same diameter partially projecting from the gun barrel.

The velocity of the impacting rod was measured in the space between the end of the gun barrel and the impact face of the target rod using a pair of light gates, each consisting of a diode laser and photodiode. The second laser beam was positioned close to the impact face. The distance between the end of the gun barrel and the impact face was set so that approximately $25 \%$ of the impacting rod (i.e. about $15 \mathrm{~mm}$ for a $63 \mathrm{~mm}$ long rod) was still in the barrel at the moment of impact. Having a short length of the moving rod still in the barrel at impact improves the planarity of impact without risking plastic deformation of the rod interacting with the end of the gun barrel. The output of the photodiode closest to the point of impact was used to trigger the camera and PDV system.

\section{Results}

Selected frames from a high-speed photographic sequence are presented in Fig. 2 for symmetric Taylor impact

This is an Open Access article distributed under the terms of the Creative Commons Attribution License 4.0, which permits unrestricted use, distribution, and reproduction in any medium, provided the original work is properly cited. 


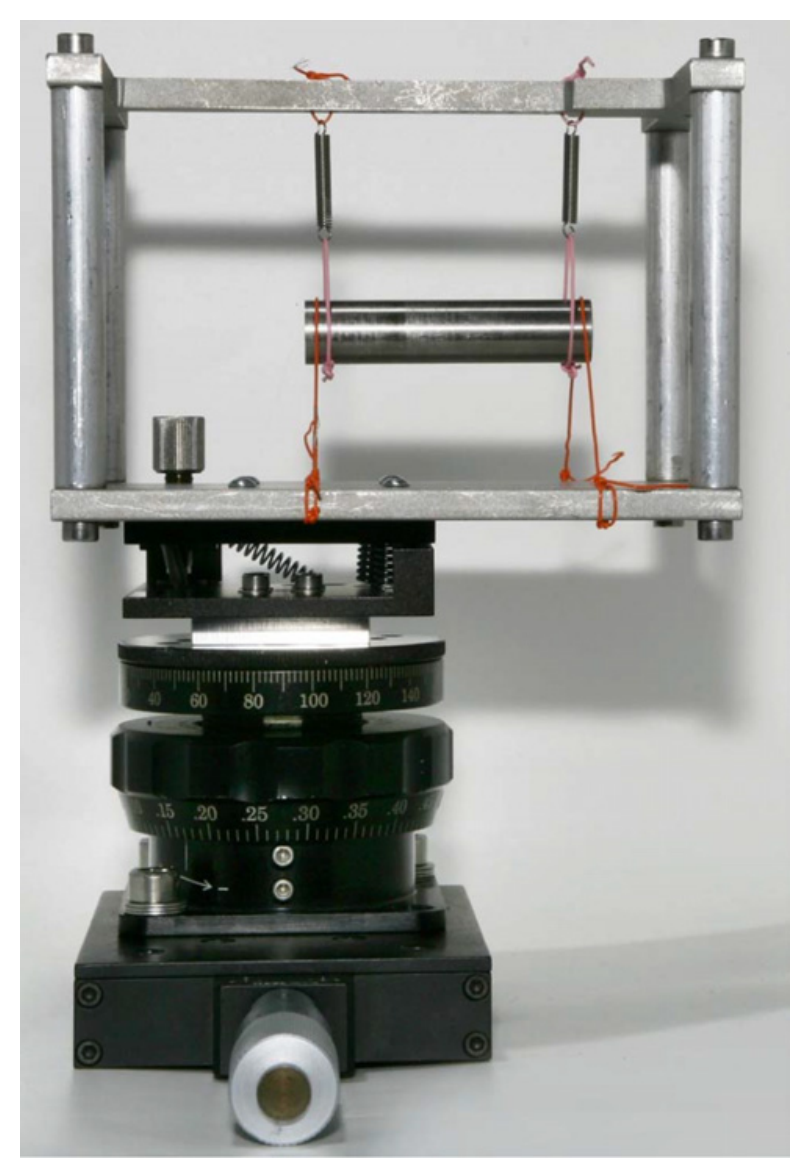

Figure 1. Photograph of wire cradle for holding a target rod prior to mounting in the target chamber. The rod shown is $63.3 \mathrm{~mm}$ long and $12.66 \mathrm{~mm}$ diameter. In use, the projectile rod enters and strikes the target rod from the right hand side (see Fig. 2).

at $334 \mathrm{~m} \mathrm{~s}^{-1}$ of $99.999 \%$ pure aluminium supplied by Goodfellow Metals. The interframe time was set to $10 \mu \mathrm{s}$ on the Vision Research Phantom 711 camera used. The time at which impact occurred (137.2 $\mu$ s after trigger) was determined by digitising the coordinates of the ends of the rods in each frame and interpolating to the point of impact.

It can be seen that during the first stage of impact, the sides of the target rod are concave near the impact face. However, about $80 \mu \mathrm{s}$ after impact (frame (d)) the rod begins to bulge outwards plastically some distance back from the impact face. This phenomenon has been seen before for copper [4] and is characteristic of fcc materials. In the full sequence, the rods can visibly be seen to start to separate about $200 \mu \mathrm{s}$ after impact (340 $\mu$ s after trigger) and continue to draw apart as the sequence continues (see Fig. 2(g)).

Photon Doppler Velocimetry (PDV) [10,11] was also used to record the motion of the rear of the target rod (Fig. 3). The rear of the rod can be seen to accelerate smoothly but at an increasing rate. However, the PDV trace presented in Fig. 3 ends abruptly before the two rods separated. This is because the target rod struck the PDV's optical fibre (see Fig. 2(f)).

It is instructive to consider what velocity we would expect for two extremes of behaviour. If the system behaved as a 'Newton's cradle' $[12,13]$ (i.e. perfectly
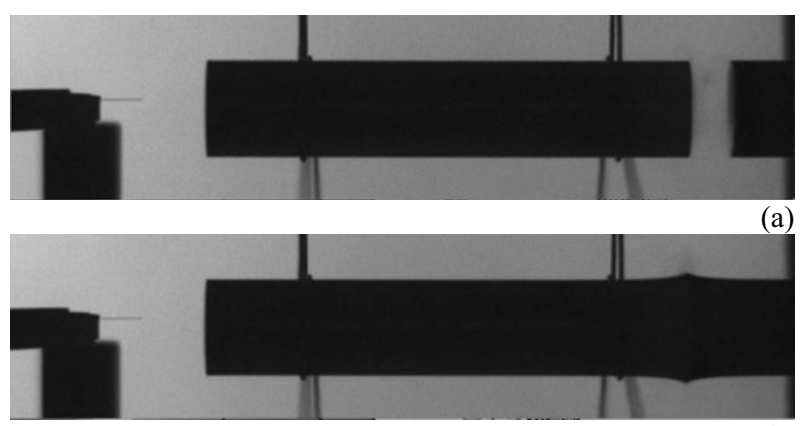

(a)

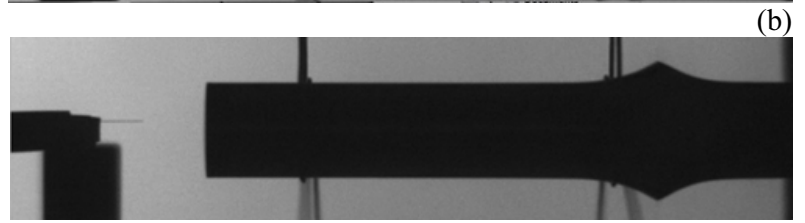

(c)

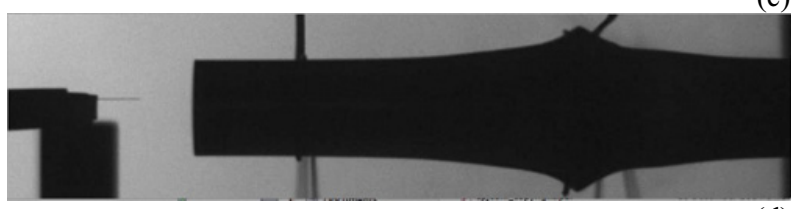

(d)

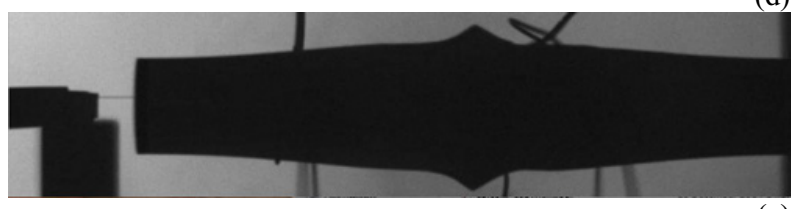

(e)

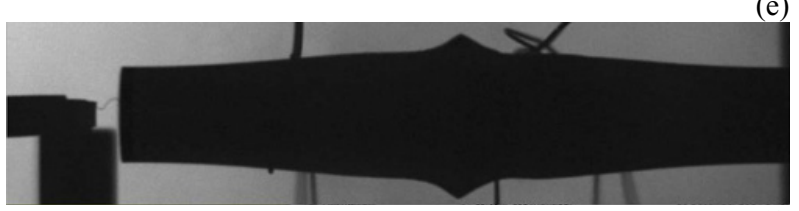

(f)

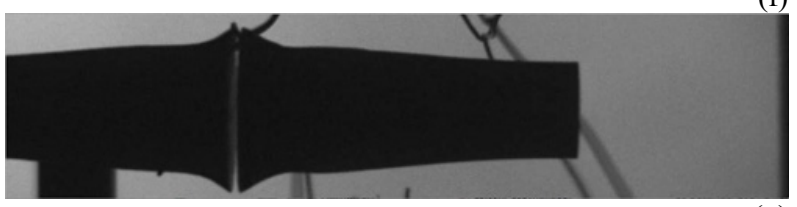

(g)

Figure 2. Selected frames from the high-speed photographic sequence of a $63.3 \mathrm{~mm}$ long, $12.66 \mathrm{~mm}$ diameter pure aluminium rod being impacted at $334 \mathrm{~m} \mathrm{~s}^{-1}$ by another identical pure aluminium rod. The camera used was a Vision Research, Phantom 711. The PDV probe can be seen to the left behind the target rod. Note that the block below the PDV optical fibre probe is not in the impact plane. Times of each frame from trigger: (a) $120 \mu \mathrm{s}$ (b) $140 \mu \mathrm{s}$ (c) $160 \mu \mathrm{s}$ (d) $220 \mu \mathrm{s} \mathrm{(e)} 300 \mu \mathrm{s}$ (f) $310 \mu \mathrm{s} \mathrm{(g)}$ $480 \mu \mathrm{s}$.

elastically), the projectile rod would come to a dead stop and the target rod would depart at the impact velocity of the projectile rod. On the other hand, if the two rods plastically deformed and joined together, they would continue on at half the impact velocity. Since the observed mechanical behaviour is intermediate between these two extremes, the projectile rod should continue moving at less than the impact velocity while the target rod exits the impact at slightly more than half the impact velocity. This was confirmed by another experiment on pure aluminium performed at $151 \mathrm{~m} \mathrm{~s}^{-1}$ where PDV showed that the final 


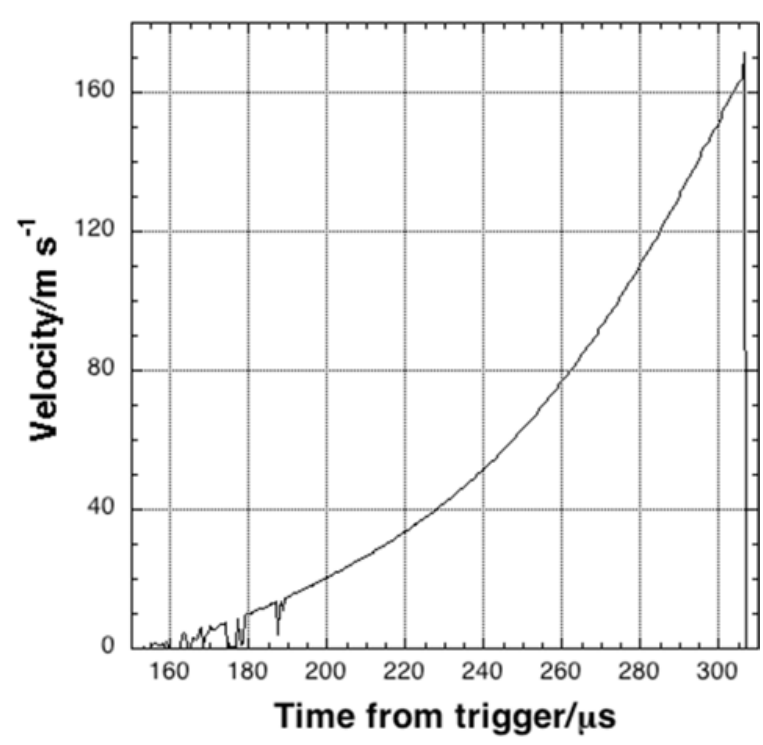

Figure 3. Velocity-time plot of the rear of target rod obtained using PDV. The sudden drop at $306.4 \mu$ s corresponds to when the target rod struck the optical fibre. This occurred before the two rods separated.

velocity of the target rod was $83.6 \mathrm{~m} \mathrm{~s}^{-1}$ as compared to $151 / 2=75.5 \mathrm{~m} \mathrm{~s}^{-1}$ if the two rods had stuck together.

It is clear from the argument just given and from Fig. 2(g) that the velocity difference between the two rods is sufficiently small that they only gradually separate from each other. Thus a soft capture method had to be developed to ensure they did not collide a second time during deceleration. After some experimentation, a tube containing approximately $40 \mathrm{~cm}$ of expanded polystyrene beads (diameter $2-5 \mathrm{~mm}$ ) backed by rags to a similar depth was found to work in that both rods were recovered in almost the same condition that they left the impact zone (see Fig. 4). There is a small visible asymmetry in the deformation (see Fig. 4(b)) in that the impact surface of the target rod has a depression in the centre while the projectile rod has a corresponding bulge. One possible explanation is that the cylindrical surface of the projectile rod was frictionally heated during acceleration in the gun barrel producing a cylindrical annulus of softened metal in the projectile rod.

Rod profiles (Fig. 5) were obtained from the highspeed photographic sequence shown in Fig. 2. The profiles of both the upper and lower edges of the target rod are separately plotted in order to check for symmetry of deformation. These profiles are at present being compared with numerical predictions based on constitutive models.

It can be seen from Figs. 5(a) and 5(b) that the plastic deformation is initially close to symmetric, the profiles being concave near the impacted end. Figure 5(a) represents the deformation $2.8 \mu \mathrm{s}$ and Fig. 5(b) $62.8 \mu \mathrm{s}$ after impact. Figures 5(c) and 5(d) show that at a later stage the deformation becomes more complex with a second bulge forming between about 6 and $30 \mathrm{~mm}$ from the impact face. At the same time the difference between the upper and lower profiles became greater.

$\mathrm{X}$-ray tomography was used to examine the recovered rods for voids (Fig. 6). Such voids had previously been
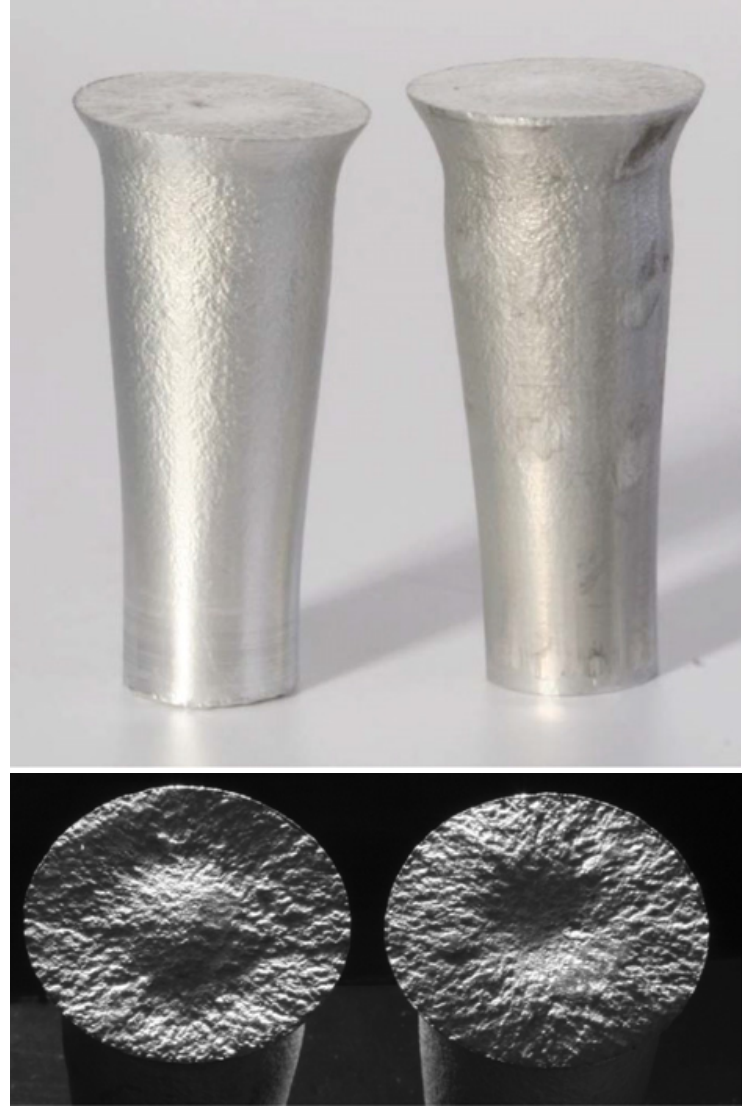

(a)

(b)

Figure 4. Photographs of pure aluminium rods soft-recovered after rod-on-rod impact at $334 \mathrm{~m} \mathrm{~s}^{-1}$ (same rods as shown in Fig. 2). (a) Side view: the right hand rod is the projectile rod; (b) Top view: the left hand rod is the projectile rod.

seen in symmetric Taylor impact [5]. It can be seen from Fig. 6 that voids were indeed formed. The voids show up as black dots close to the impact surface in Fig. 6(a). However, they are small and off-axis (see Fig. 6(b)). They might therefore easily have been missed if the rods had been physically sectioned.

\section{Summary}

(i) A novel wire-cradle arrangement has been designed and used to hold the target rod for symmetric Taylor impact experiments. The wire-cradle exerts a very small constraint on the deformation of the target rod.

(ii) Two diagnostics were applied to study the dynamic deformation of the target rod: high-speed photography and Photon Doppler Velocimetry (PDV).

(iii) A soft-recovery system was designed to ensure that the two rods did not collide a second time during deceleration. The system consists of a tube partially filled with expanded polystyrene foam beads backed with rags.

(iv) Recovered rods were examined using X-ray tomography to determine whether voiding had occurred. Aluminium rods subjected to an impact velocity of $334 \mathrm{~m} \mathrm{~s}^{-1}$ clearly contained voids close to the axis near the impact face.

(v) PDV showed that for the aluminium rods the rears of the target rods accelerated smoothly at an increasing rate 

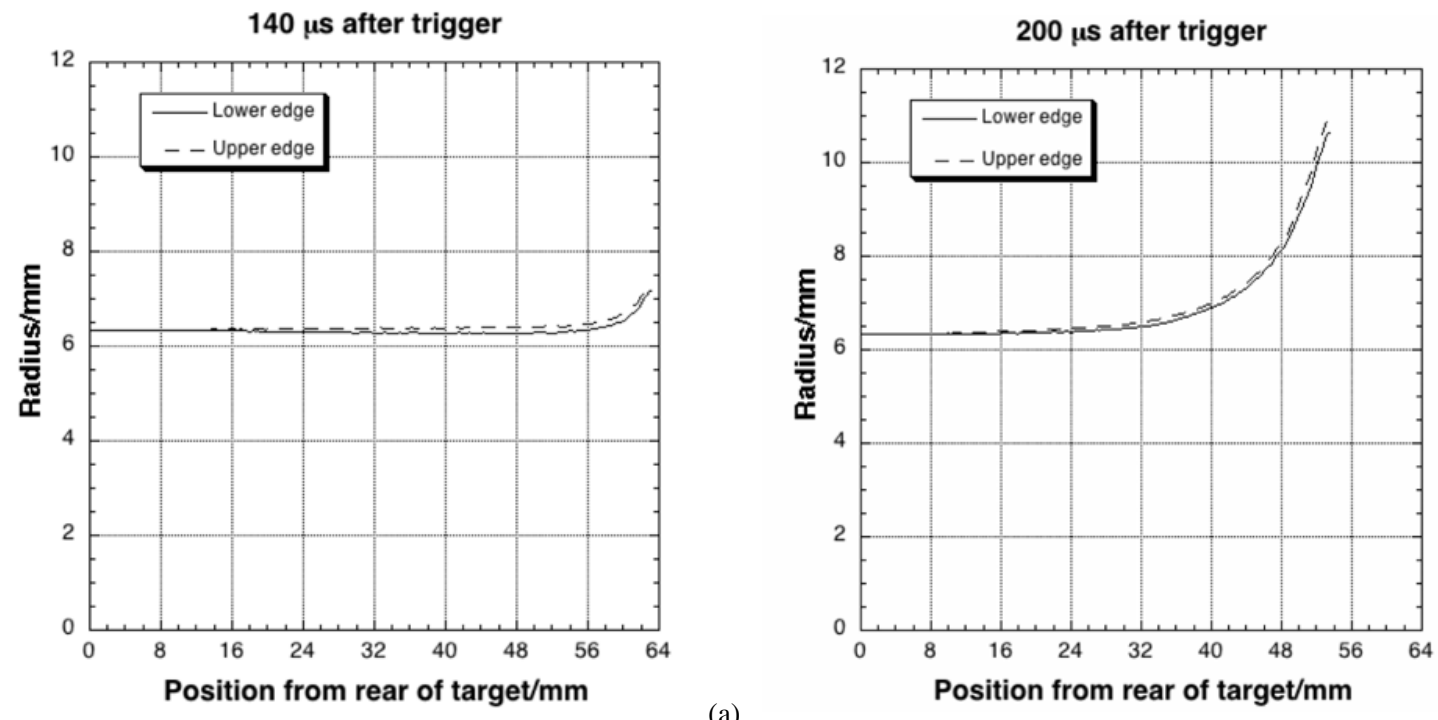

(a)

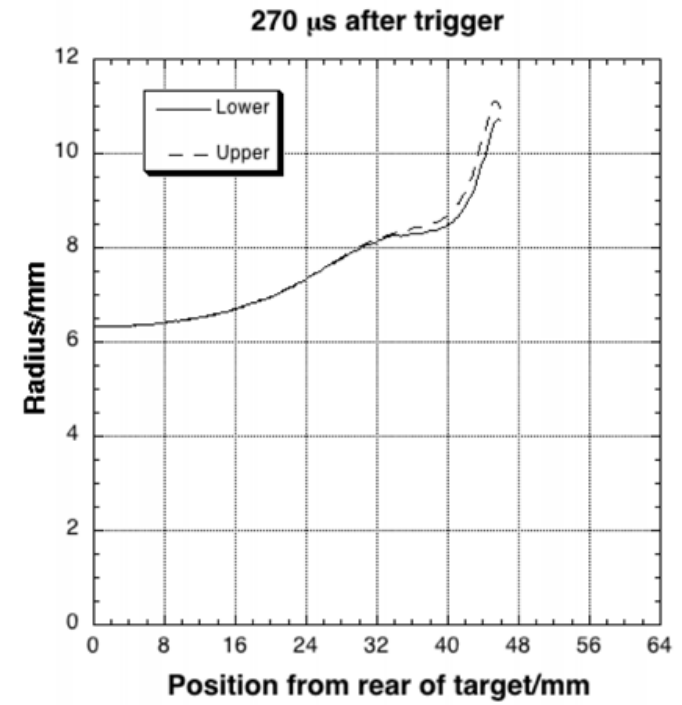

(c)

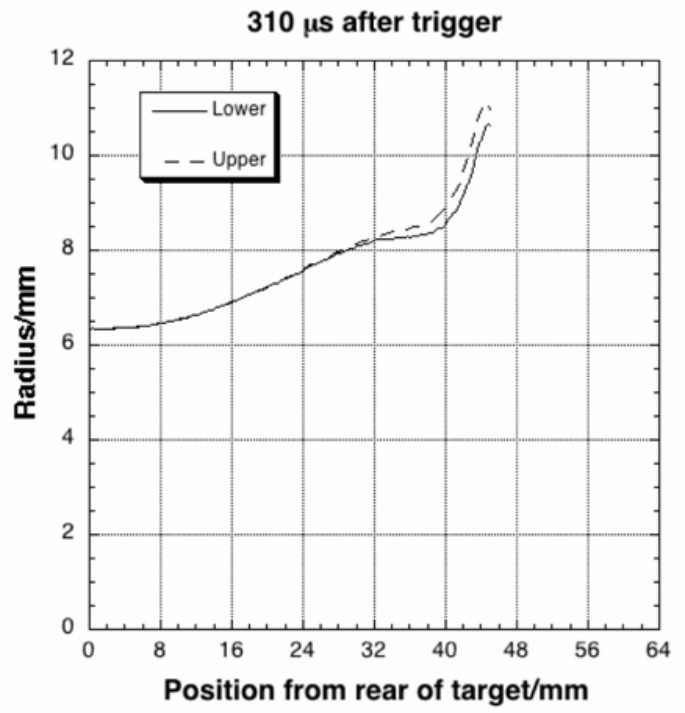

(d)

Figure 5. Profiles of selected frames from the high-speed photographic sequence of the impact shown in Fig. 2. Impact took place 137.2 $\mu$ s after trigger. Distances (radii) to the upper and lower edges of the rod are measured from the centre line of the rod.
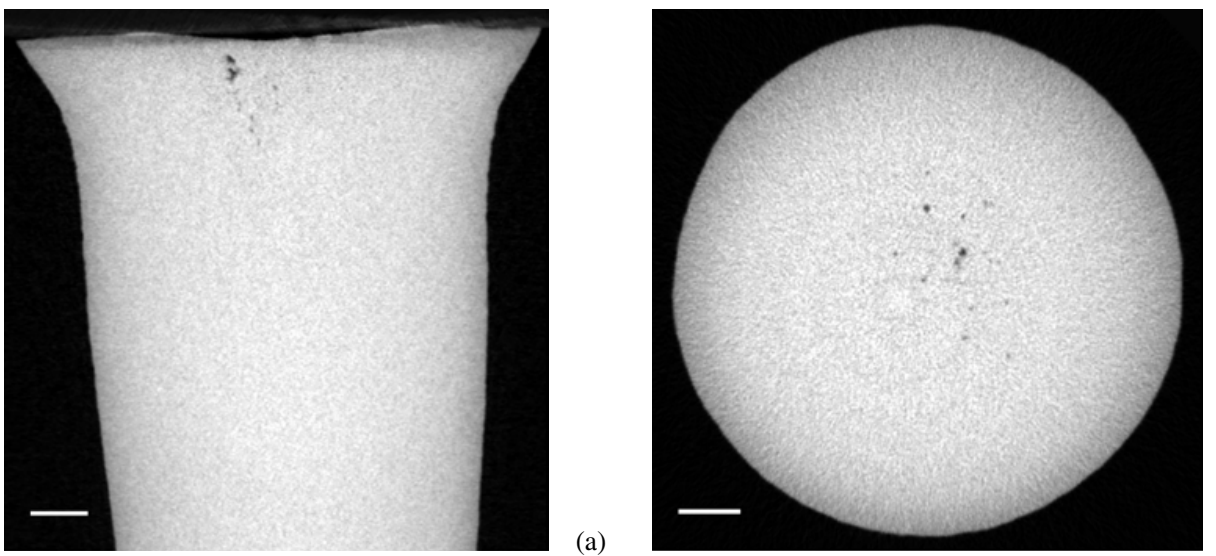

(b)

Figure 6. X-ray tomographs of aluminium projectile rod after impact with a stationary aluminium rod at $334 \mathrm{~m} \mathrm{~s}^{-1}$. (a) Side view. (b) End view close to the impact surface. Scale bars represent $3 \mathrm{~mm}$. 
(characteristic of the deformation process) to a maximum velocity slightly greater than that for a perfectly plastic collision.

This research was supported by grants from the British Ministry of Defence through QinetiQ Fort Halstead. The authors would like to thank I.G. Cullis, P.D. Church and P.J. Gould for their interest.

\section{References}

[1] D.C. Erlich, D.A. Shockey and L. Seaman, Shock Waves in Condensed Matter - 1981, pp. 402-406 (American Institute of Physics, New York, 1982)

[2] D.C. Erlich, Metals Handbook. Vol. 8 (9th edn.), pp. 203-207 (American Society of Metals, Metals Park, Ohio, 1985)

[3] H. Couque, J. Phys. IV France 10 (Pr. 9) 179-184 (2000)

[4] S.M. Walley, P.D. Church, R. Townsley and J.E. Field, J. Phys. IV France 10 (Pr. 9) 69-74 (2000)

[5] D.J. Chapman, D.D. Radford, M. Reynolds and P.D. Church, Int. J. Fract. 134, 41-57 (2005)
[6] H. Couque, G. Nicolas and C. Altmayer, Int. J. Impact Engng 34, 412-423 (2007)

[7] L.C. Forde, W.G. Proud and S.M. Walley, Proc. R. Soc. A 465, 769-790 (2009)

[8] L.C. Forde, S.M. Walley, M. Peyton-Jones, W.G. Proud, I.G. Cullis and P.D. Church, Proc. 9th Int. Conf. on the Mechanical and Physical Behaviour of Materials under Dynamic Loading (DYMAT 2009), pp. 1245-1250 (EDP Sciences, Les Ulis, France, 2009)

[9] W. Mocko, J. Janiszewski, J. Radziejewska and M. Grazka, Int. J. Impact Engng 75, 203-213 (2015)

[10] M. Durand, P. Laharrague, P. Lalle, A. Le Bihan, J. Morvan and H. Pujols, Rev. Sci. Instrum. 48, 275278 (1977)

[11] O.T. Strand, D.R. Goosman, C. Martinez, T.L. Whitworth and W.W. Kuhlow, Rev. Sci. Instrum. 77, 083108 (2006)

[12] D.R. Lovett, K.M. Moulding and S. Anketell-Jones, Eur. J. Phys. 9, 323-328 (1988)

[13] V. Ceanga and Y. Hurmuzlu, J. Appl. Mech. 68, 575-583 (2001) 